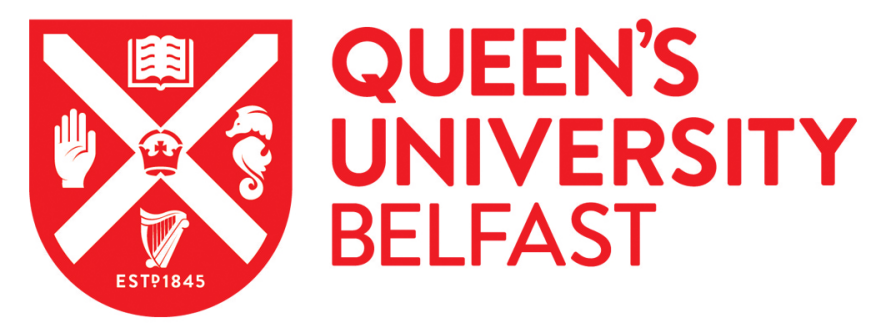

\title{
Feeling for Meaning: The making and understanding of Image Theatre
}

Grant, D. (2017). Feeling for Meaning: The making and understanding of Image Theatre. Research in Drama Education: The Journal of Applied Theatre and Performance . https://doi.org/10.1080/13569783.2017.1286977

Published in:

Research in Drama Education: The Journal of Applied Theatre and Performance

Document Version:

Peer reviewed version

Queen's University Belfast - Research Portal:

Link to publication record in Queen's University Belfast Research Portal

Publisher rights

(C) 2017 Informa UK Limited, trading as Taylor \& Francis Group.

This work is made available online in accordance with the publisher's policies. Please refer to any applicable terms of use of the publisher.

\section{General rights}

Copyright for the publications made accessible via the Queen's University Belfast Research Portal is retained by the author(s) and / or other copyright owners and it is a condition of accessing these publications that users recognise and abide by the legal requirements associated with these rights.

Take down policy

The Research Portal is Queen's institutional repository that provides access to Queen's research output. Every effort has been made to ensure that content in the Research Portal does not infringe any person's rights, or applicable UK laws. If you discover content in the Research Portal that you believe breaches copyright or violates any law, please contact openaccess@qub.ac.uk. 


\section{Feeling for Meaning: the making and understanding of Image Theatre}

\section{Abstract}

Using iconic images created by students in Belfast and Sarajevo of their respective cities, this paper will explore how emerging ideas in the field of cognitive science (e.g. Gallagher, 2005) can help explain the making and understanding of Augusto Boal's 'Image Theatre'. There has been growing interest in the intersection between performance and cognitive science (McConachie, 2006), particularly in terms of kinaesthetic empathy (Reynolds and Reason, 2012), which can enhance our understanding of the embodied practices associated with Augusto Boal's Image Theatre' (Boal, 1992). This paper will analyse the ambiguities inherent in stage images of contested cities to explore how these may reveal unconscious insights into the image-makers' perception of their home environments. An image of Sarajevo, for instance, ostensibly about the Winter Olympics, prompts consideration of the city's internal divisions. An image of Belfast, ostensibly about the Titanic, suggests the limitations of the city's Peace Process. Taking Boal's idea that stage images should be felt rather than read, this article explores the fine line between feeling and meaning in the understanding of Image Theatre and suggests that alongside literacy and orality we now also need to include 'imageracy', the ability to interpret and understand images, as a key competency in the modern world.

\section{Image Theatre}

Image Theatre has been rightly described as 'the analytical basis of Brazilian theatre director Augusto Boal's system of the Theatre of the Oppressed' (Perry, 2012, p. 103) and yet in most academic writing about Theatre of the Oppressed (TO) it is seen simply as a means to the end of more developed techniques such as Forum Theatre or the Rainbow of Desire. This article aims to address this lacuna in Boal scholarship by focussing directly on the way in which stage images are both made and understood. Boal's own published work provides a good basis for this discussion, but emerging developments in psychology are providing new insights into the cognitive processes that underpin Image Theatre practice. The article will also draw on my own twenty years of experience of Augusto Boal's Image Theatre techniques to provide working examples.

By Boal's own account, the use of stage images in TO arose from his growing awareness of the unhelpful ambiguity of spoken verbal language, especially when he was working through Spanish with participants who had a variety of other mother tongues. 'We must never forget,' he reminds us, 'that words are only vehicles which convey meanings, emotions, memories, ideas... which are not necessarily the same for everyone: the word spoken is never the word heard.' (Boal, 2002, p. 174). In this, Boal echoes George Steiner's famous dictum that: 'Any model of communication is at the same time a model of trans-lation [sic]... No two historical epochs, no two social classes, no two localities use words and syntax to signify exactly the same thing, to send identical signals of valuation and inference. Neither do two human beings' (Steiner, 1998, p. 47). Boal discovered that still images, made using the participants' bodies, provided an alternative way of sharing ideas which were less dependent on verbal language. These early experiments with what he initially called 'Statue Theatre' because of the static nature of the imagery, quickly developed into Image Theatre as the images were animated (or 'dynamised') through the addition of movement. 


\section{Making Stage Images}

A Boal 'stage image' can be created in a number of ways. One individual can craft a group image by demonstrating the required body shapes to other group members, often showing them the facial expression they should adopt - what Boal calls mirror language. 'This image can be realistic, allegorical or surrealistic, it can be symbolical or metaphorical. The only thing that matters is that it is true, that it is felt as true by the protagonist [the image maker]' (1995, p. 77). Alternatively, they can 'sculpt' the image by physically manipulating the limbs of other participants - the language of

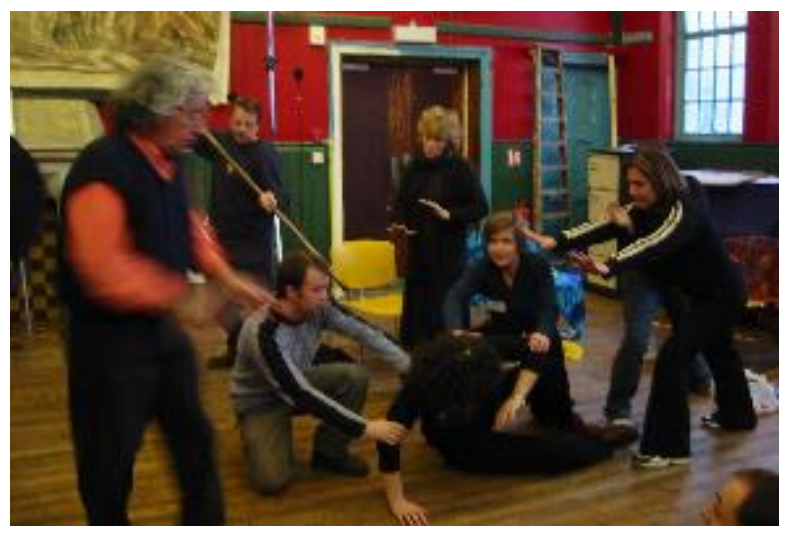

modelling. This usually also requires some degree of demonstration, but explanation should be avoided. 'It is important that the person who is "sculpting" works fast, so that she will not be tempted to think in words (verbal language) and then translate them into images (visual language)' (1992, p. 181). For as Boal (pictured left) insists: 'Dealing with images we should not try to 'understand' the meaning of each image, to apprehend its precise meaning, but to feel those images, to let our memories and imaginations wander. Images don't replace words but they cannot be translated into words either - they are a language in themselves' (2002, p. 175).

Boal's emphasis on respecting the inherent visual meaning of stage images echoes that of Strecker, a visual ethnographer, who notes that: "We tend to "stand between" the image and audiences by translating images into words. In doing so we impose one interpretation on the images, thus dismissing the possibility that the images may have more than one meaning' (1997). As Boal himself explains:

The meaning of an image is the image itself. Image is a language... If an image is interpreted in just the one way... it ceases to be Image Theatre and becomes a mere illustration of the words spoken. Image Theatre is a sinaletic method, not a symbolic one: in the latter signifier and signification are separate; in the former signifier and signification are the same thing... the "thumbs-up" gesture for 'OK' is symbolic, a look of sadness is sinaletic ${ }^{1}$. (Boal, 2002, p. 175)

This distinction, when illustrated with these simple examples seems straightforward enough, but once we try and apply it to the more complex dramaturgy of a full stage image it becomes more difficult to distinguish the symbolic from the sinaletic. Some elements of the image may seem closer to the "thumbs-up" gesture in that we read them in a symbolic way, others we may understand more phenomenologically through an empathetic engagement with the feelings they express, while still more may combine both modes of expression. Psychologist, Shaun Gallagher's work on the relationship between spoken language and physical gesture provides a helpful analogy in trying to unravel these differences. By establishing a direct link between thought and action, he may have

\footnotetext{
${ }^{1} \mathrm{~A}$ Boal coinage, based on the French 'signalétique'
} 
provided the key to understanding how stage images appear sometimes to tap into our unspoken thoughts.

\section{An Embodied Practice}

As Boal understood well, Image Theatre is an embodied process in which we think through our bodies:

\footnotetext{
We start from the principle that the human being is a unity, an indivisible whole. Scientists have demonstrated that one's physical and psychic apparatuses are completely inseparable. Stanislavsky's work on physical actions also tends towards the same conclusion, i.e. that ideas, emotions and sensations are all indissolubly interwoven. A bodily movement 'is' a thought and a thought expresses itself in corporeal form... (Boal, 2002, p. 49)
}

Boal's holistic approach challenges the conventional wisdom that treats verbal language as the sole medium for thought, collapsing the distinction between language and gesture and leading us towards an understanding of image-making and reading that is at least as much phenomenological as semiotic: hence the idea that we can 'feel' meaning.

Shaun Gallagher makes an even more direct connection between speech and movement, invoking Merleau-Ponty who argued that 'the body converts a certain motor essence into vocal form' (1962, p. 181). Viewed in this way, the linguistic idea of the 'speech-act' becomes literal rather than figurative. But Gallagher goes further, suggesting '[o]ne could imagine gesture as the origin of spoken language... A special kind of oral motility. Speech on this view would be a sophisticated movement of the body' (ibid.), as if the vocal fold was a sophisticated muscle, and the organs of articulation tiny limbs. 'Gestures', he concludes, '.. are both products and active producers of... brain organisation' (ibid. p. 128). In a series of experiments with a subject (IW) who was paralysed from the neck down, losing all sense of proprioception (awareness of his own body), Gallagher with his colleagues Jonathan Cole and David McNeill, demonstrated that IW could only move his limbs at will when he could see them. If his arms and hands were masked from his view, however, he nevertheless made involuntary gestures associated with his speech patterns in a similar way to those normally observed in the able-bodied. Gallagher uses this exceptional case to argue the distinction between body image and body schema.

A body image consists of a system of perceptions, attitudes and beliefs pertaining to one's own body, originating in a self-referential consciousness directed toward one's own body. A body schema is a system of processes that constantly regulate posture and movement. It consists of motor capacities that are in part governed by sensory feedback but that function without body awareness or the necessity of perceptually monitoring the body... Although it is possible to make a conceptual distinction between body image and body schema... in the normal case [they] are quite integrated in their functioning. (Cole et al., 2002, p. 51)

What made IW's case so unusual was how the dysfunction of his body schema means that: 
his body completely lacks the information provided by proprioception and touch. When in darkness or with his eyes closed, IW does not know where his limbs are. On the other hand, with his eyes open and the lights on, IW is capable of using visual aspects of his body image to control his movements in quite precise ways' (ibid, pp. 5253).

Gallagher uses the fact that IW's speech-related gestures functioned normally even when he could not consciously monitor them, as evidence for his 'communicative theory of gesture' that 'gestures are primarily part of communicative action rather than a form of motor behaviour [sic]' (ibid., p. 59). Noting that 'Merleau-Ponty tells us that language does not simply externalise or communicate a pre-formed thought; rather, language accomplishes thought' Gallagher goes on to ask: 'Is it possible that gesture itself, as language rather than movement, assists in the accomplishment of thought?' (ibid. p. 62). Although Gallagher is concerned mainly with the inter-relationship of spoken language and its associated gestures, it is a tantalising possibility that at least some component of a stage image may draw directly on unverbalisable embodied thoughts. This idea of gesture-as-language, of movement itself as a primary vehicle for thought, is implicit in Boal's own explanation of movement in Image Theatre as thought expressed in corporeal form. Wittgenstein's famous conclusion, "whereof one cannot speak, thereof one must be silent" does not, after all, preclude recourse to movement.

\section{Examples from Practice}

In order, therefore, to allow the visual to predominate and to minimise verbal mediation in the imagemaking process, my own preferred approach to Image Theatre is for an image to accumulate, body by body, with each contributor adding spontaneously to the overall picture with the minimum of verbal mediation. The sequence of photographs below illustrates an accumulative image-making process in Belfast in 2012 in which participants responded to an invitation to create an image of Belfast itself. Each consecutive response was based on the new contributor spontaneously engaging with the previous accumulated image in an embodied way.
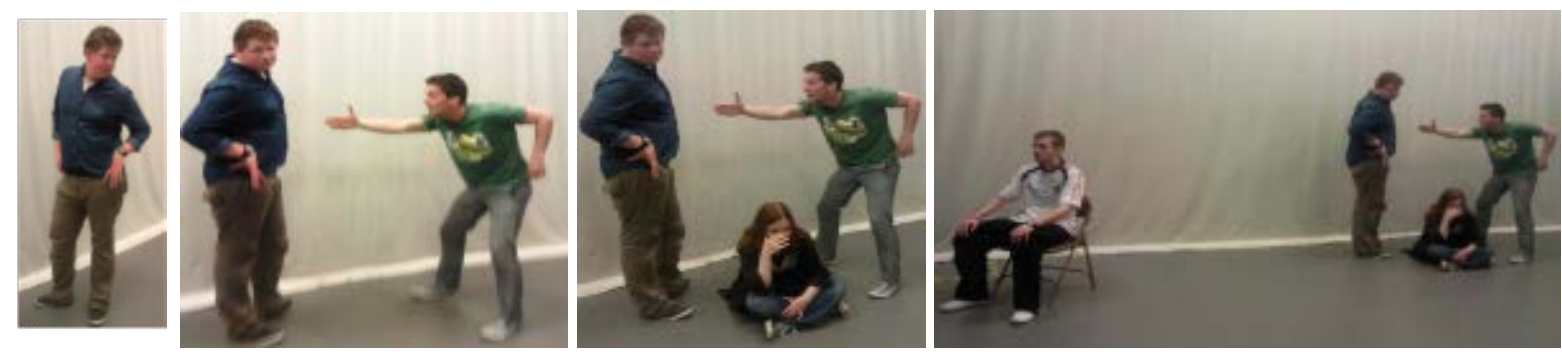

An analysis of this process based on the difference between body image and body schema allows a distinction to be drawn between those aspects of the image which derive from each participant's active awareness of how they position their own body, and those aspects which emerge from beneath their surface consciousness. Because of their conscious initiation, the former can be described as semiotic and 'meant'; the latter more subliminal elements of the image including the subtle nuances of gesture, posture and facial expression which often have a disproportionate impact on the observers of the image, can be seen as phenomenological and 'felt'. While working through the 
use of images rather than through verbal discussion helps ensure that the phenomenological dimension of the process remains predominant, inevitably a semiotic reading still contributes to each actor's response. In their approach to the emerging image as observers, participants both feel the meaning and engage in a reading of gesture, body language and facial expression. The emphasis on the visual, however, helps to encourage a greater reliance on the group members' sense of embodied intersubjectivity.

Boal has much to say about the collective nature of image making.

In our daily lives we are the centre of our universe and we look at facts and people from a single perspective, our own. On stage we see the world as we have always seen it, but now we also see it as others see it: we see ourselves as we see ourselves, and we see ourselves as we are seen.' (1995, p. 26)

He calls this liminal relationship between reality and its image metaxis: 'the state of belonging completely and simultaneously to two different, autonomous worlds: the image of reality and the reality of the image' (1995, p. 13). As Perry explains, participants in an Image Theatre workshop 'inhabit both of these worlds at once: they are grounded in both aesthetic space (the image of reality) while simultaneously articulating and reflecting on how their aesthetic creations are rooted in the social world (the reality of the image).' (2012, p. 107) In the example above, as each workshop participant engages with and contributes to the emerging final image they inhabit this in-between world, giving themselves over to an unaccustomed embodied mode of analysis. '[D]ealing with images, in contrast to words, prioritises a way of knowing that necessarily involves the body as well as the intellect' (Perry , p. 107). A common challenge, then, when working in Image Theatre is the difficulty of encouraging participants, educated primarily through written and spoken verbal language to rely on physical, gestural expression without resorting to speech.

I use an exercise called 'Samson, Delilah and the Lion', in which participants create images using their whole bodies as a way of preparing image-makers to express themselves in a fully embodied way. Here, members of the group work in pairs: back-to-back each decide on one of three

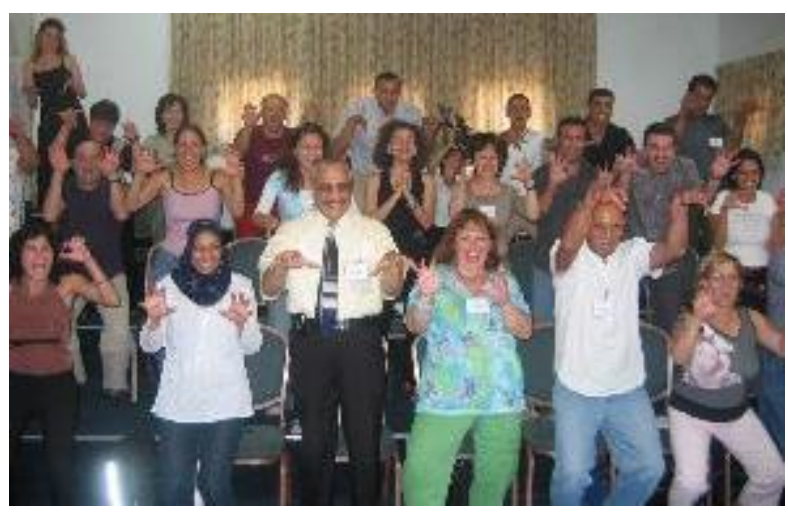
embodied images to demonstrate to their partner, turning to face one another on a count of three. The game is akin to 'Rock, Paper, Scissors' in that each element has a 'weaker' and a 'stronger' counterpart - Samson is stronger than the Lion and weaker than Delilah, who is stronger than Samson and weaker than the Lion, which in turn is stronger than Delilah and weaker than Samson. The hilarity the game invariably generates (evident in this photograph from a workshop in Jerusalem with Jewish and Palestinian school teachers in the initial stages of the exercise in which they learnt to exercise together before splitting into pairs), helps participants to free themselves from inhibitions that can prevent them giving 
themselves over to the unfamiliar reliance on the visual rather than the verbal. By acclimatising them to work through a visual medium, the hidden world of their embodied thinking becomes easier for them to access.

To prepare the observers of stage images, on the other hand, to respond to visual meaning, I have tended to rely on a variant of Boal's 'Great Game of Power' where audience members respond to images created by one of their number using four chairs (2002, p. ??). The image-maker is invited to make one chair more important than the others by moving one or more of them within the 'aesthetic space' which is TO's flexible platform. However simple an image may appear, there is usually some division of opinion within the audience about which has become the most important. Quite often, for instance, the image-maker will place one of the four chairs facing the other three, which some observers will interpret as a classroom, others as a tribunal. In the classroom version, the teacher standing alone at the front seems more important. In the tribunal, it is the chair of the tribunal (or of the interview committee) who has the dominant role. Through discussion of the exercise, the group can be encouraged to recognise that each interpretation has equal validity, and individuals in the group become more confident in their own subjective interpretation of images they go on to create together. The readiness to accept the possibility of multiple coexisting meanings is vital for effective Image Theatre.

\section{Unknown Unknowns}

As Boal's famous neologism spectactor implies, as well as connecting the embodied thoughts of image-makers, metaxis also collapses the distinction between artist and audience. As each participant connects with the image-making process, they are at one-and-the-same-time agents and observers. By contributing to the image they are simultaneously commenting on it:

As objects reflect the light that strikes them, so images in an organised ensemble reflect the emotions of the observer, her ideas, memories, imagination, desires... The whole method of Theatre of the Oppressed... is based on the multiple mirror of the gaze of others - a number of people looking at the same image, and offering their feelings, what is evoked for them, what their imaginations throw up around that image. This multiple reflection will reveal to the person who made the image its hidden aspects.' (Boal 2002, p. 175)

The 'hidden aspects' Boal refers to can be thought of as 'unknown knowns'. This was the missing component in former U.S. Secretary of Defence, Donald Rumsfeld's infamous epistemological taxonomy when he spoke of 'known knowns' (the things we know we know), 'known unknowns' (the things we know we do not know) and 'unknown unknowns' (the things we don't know we don't know) ${ }^{2}$. He omits to mention the things we know that we don't know we know. For the most remarkable aspect of my own Image Theatre practice has been the many occasions on which the

\footnotetext{
${ }^{2}$ Feb. 12 2002, Department of Defense news briefing
} 
makers of stage images acknowledge the validity (or at least the possibility) of the unexpected meanings others see in them.
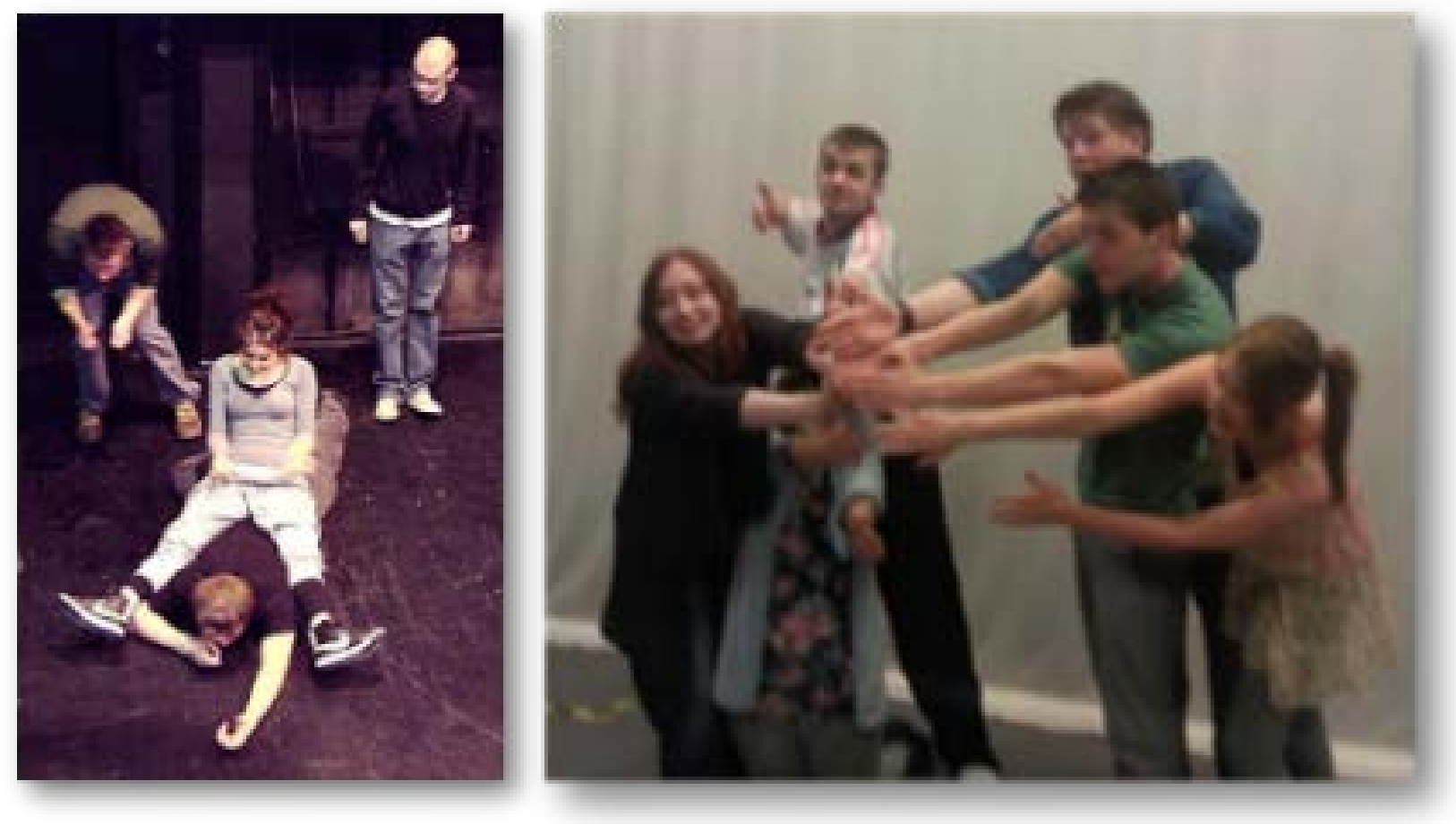

To give two examples, the image on the left was created by local drama students in a workshop I facilitated in Sarajevo in 2010. The image on the right was created by drama students in Belfast in 2011. In each case the brief was to create an image of their own city. The stated intention of the Sarajevo students was to create an image of the Winter Olympics, which even after an intervening Civil War is the way they choose to present their city to the world. The stated intention of the Belfast students was to create an image of the Titanic, of which Belfast remains ironically proud. ("It was alright when it left here!"). But when other members of the group were invited to interpret these images, several reported seeing a sniper in the foreground of the first image; and in the second image hints of an unresolved peace process - many hands held out but none reciprocated with a handshake. Once presented with these alternative readings, most of the originators of each image were content to accept this as a legitimate parallel reading. What excites me most about the propensity of Image Theatre to generate thought-provoking alternative interpretations to those consciously intended by their creators is the possibility that these alternatives arise from a subliminal embodied thought process in their creators. If Merleau-Ponty is correct that language 'accomplishes' thought, and we accept Gallagher's argument that gesture is language, is it possible that Image Theatre can channel its makers' thoughts without recourse to words. Another image from my Sarajevo workshop may help amplify the point. 


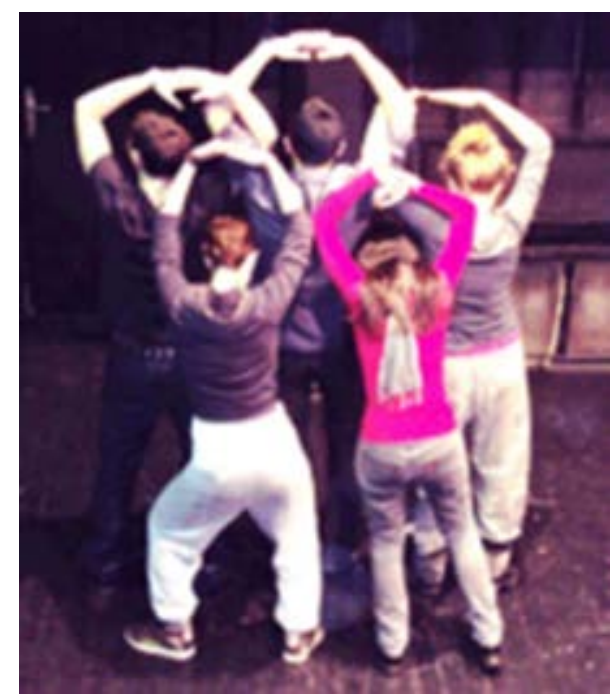

The stated intention of the local students was to present an image of the Olympic rings; but even my limited knowledge of the demographic make-up of Sarajevo could not fail to make a connection with the uneasy coexistence of different ethnic communities within the city. To my eye, the three more distant and interlinked figures represented the Bosnian Muslim community, bound together by memories of the siege; the closer, unlinked figures stood for the Serbian and Croat communities, present in the city, but separated both culturally and politically, with their own institutions. When presented with this interpretation, the image-makers themselves were surprised but not resistant to it.

\section{A Dialogue between Representation and Reality}

In the above discussion, emphasis has been placed on how the images have been perceived differently by their creators and observers. Image Theatre can best be understood as a dialogue, however, which as Mikhail Bakhtin pointed out, is initiated by the hearer, or in this case the viewer - a fact not lost on Boal:

A message does not exist without a sender and receiver. And both, receiver and sender, integrate and are contained in the message: they are part of it. (2002, p.175)

That is to say, though the making of the image is clearly dependent on the initiative of its makers, and while they themselves will certainly have a sense of what it means from within the image, its full communicative function is only realised when it is viewed by other observers. The making of meaning, therefore, is a collaborative process. So while we began with an analysis of the image-making process, we now turn to a consideration of how this relates to the reception of the image by others.

It has been the contention of this article that Image Theatre may allow image-makers to channel their subliminal thought processes - their 'unknown knowns' or 'embodied knowledge' - as arguably occurred with the Titanic and Olympic images. But how are we to understand the way in which meaning is constructed by the viewer of a stage image? In the more familiar process of vocal and aural communication, while there is of course an important paralinguistic dimension (the speaker's manner, body posture, tone and modulation of the voice), emphasis is conventionally placed on the semiotic understanding of the verbal 'signs' that comprise spoken language. But as McConachie and Hart have pointed out:

Saussurian semiotics ignores the link between language use and the cognitive unconscious... semiotic theories of human-meaning-making are seriously awry. Most cognitive scientists would agree that language has a role to play in the construction of thought, but its role derives from the embeddedness of language in the workings of the mind/brain, which is not at all 
'shapeless and indistinct' (de Saussure 1974, pp. 111-12) when it comes to making meaning. (2006, p.3)

Moreover, as has been argued above, stage images can by-pass verbal language, allowing the image-viewer too to engage directly with the embodied presence of the image-maker. To quote McConachie and Hart again:

Notions of the spectator as reader, which generally derive from language-based theories of performance, have limited our understanding of audience response. Cognitive science suggests that empathy and emotional response are more crucial to a spectator's experience than the kind of decoding most semioticians imagine (2006, 4-5).

\section{Empathy}

Invoking empathy in relation to Image Theatre is potentially problematic. In his first great treatise, Theatre of the Oppressed, Boal is famously suspicious of empathy. He urges us to understand it as 'the terrible weapon it really is' (1979, p.113), allowing the insidious morality of the world of the play to invade its audience by means of osmosis. But in The Rainbow of Desire (1995) he offers a more nuanced view, arguing that whereas in a traditional theatre:

we experience a vicarious emotion, in a Theatre of the Oppressed showing, where the oppressed themselves have created their own world of images of their own oppressions, the active observer (spectactor) - character relationship changes in essence and becomes sympathy: sym, with. We are not led, we lead. I am not penetrated by the emotion of others; instead I project my own. (1995, pp. 42-43).

The distinction Boal sets up between 'empathy: em, inside, pathos, emotion' and 'sympathy: sym, with' seems less significant, however, when viewed in the context of recent thinking about kinaesthetic empathy. Just as Boal's idea of metaxis proposes a 'state of belonging completely and simultaneously to two different, autonomous worlds: the image of reality and the reality of the image' (1995, p. 43), so the concept of kinaesthetic empathy allows us to envision a liminal relationship between the observer and the observed.

Reynolds and Reason in their edited collection of essays on kinaesthetic empathy highlight Henri Bergson's foresight when he observed that "[a]rt aims at impressing feelings on us rather than expressing them... We should have to relive the life of the subject who experiences [an emotion] if we wished to grasp it in its original complexity." (Bergson, p. 16, quoted in Reynolds \& Reason, p. 13):

For Bergson, art impresses rather than expresses feelings - this is to say that art's primary intention in a phenomenological sense of purposeful action is to convey emotions to future viewers. And, presciently suggesting the body's 'mechanical imitation' of the emotions that have been expressed in the work, Bergson opens the door for later discussions of 'mirroring'... structures that 'call forth' the psychological states originally motivating the artist's creative actions". (Reynolds \& Reason, 2012: p. 13) 
This reference to 'mirroring' relates to the emergence of a growing body of neurological evidence that empathetic responses are triggered by dedicated 'mirror neurons' which activate those parts of the human brain which would function if an observer were themselves experiencing what they see happening to others.

Thus, if in an Image Theatre workshop some of the group work together to create an image such as the Belfast and Sarajevo examples shown above, while they may initially discuss ideas between themselves, their actual process of image-making is spontaneous and collaborative, influenced by a combination of their embodied sense of themselves (proprioception) and their sensory awareness of other members of the group. The photographs (below) of an image created by drama students at the Al Midan Theatre in Haifa in 2008 vividly illustrates the visceral dimension of this part of the Image Theatre process.
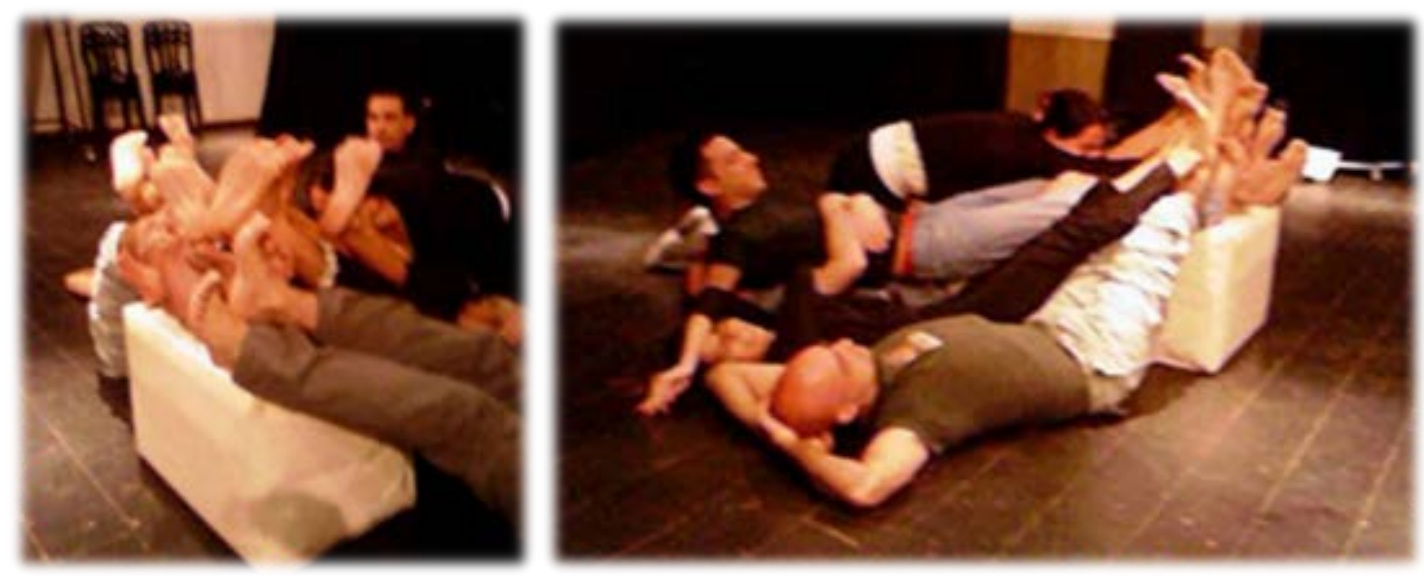

As we have seen above, this awareness will reflect a blend of the semiotic understandings they themselves assign to the elements of the image portrayed by their fellow image-makers, and also unconscious feelings that will involve some kinaesthetic empathy, as their mirror neurons 'fire' those parts of their own brains that would be active if they were making each part of the overall image themselves. This will occur even where the image is created as one action by all members of the group working in concert with one another. But it is easier to unravel when the image is created cumulatively, with each participant adding to the final image one person at a time, as illustrated in the example below - another 2011 image of Belfast by local students. Each consecutive contribution to the overall image will be influenced by a complex melange of external and internal stimuli.
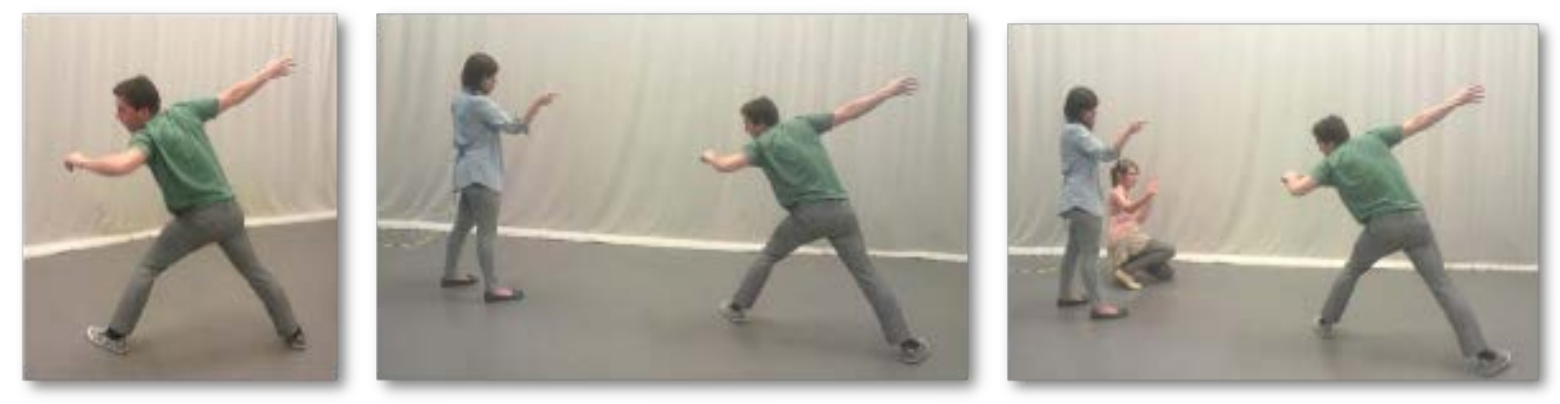

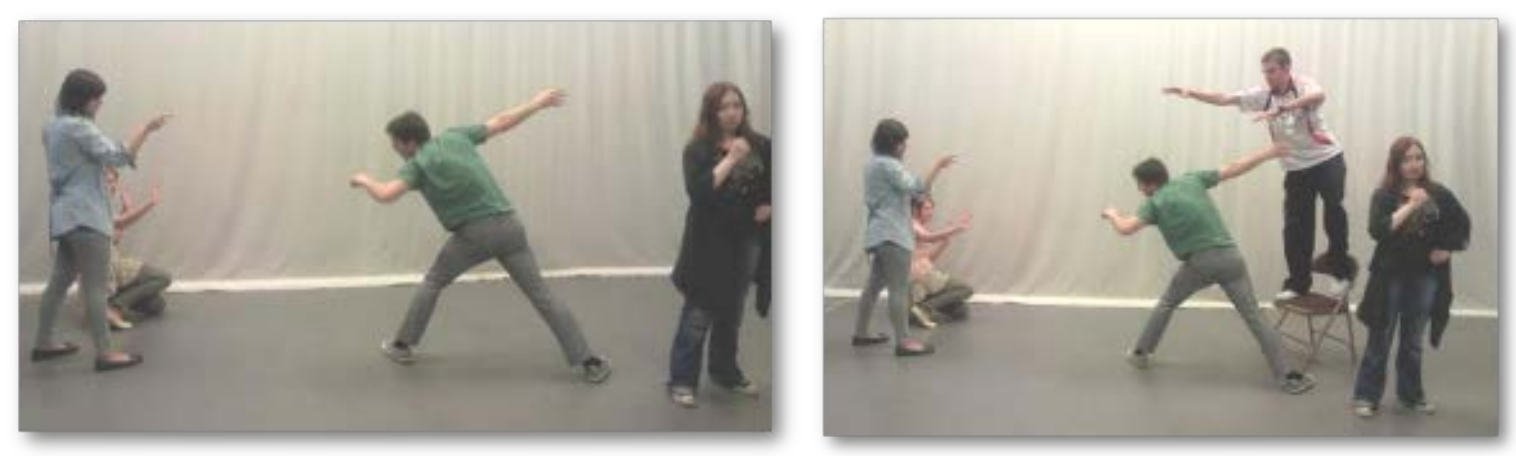

External observers sharing the experience of the image-making process are subject to a similar, if vicarious set of stimuli, reading and feeling the image as it grows.

Some post-performance workshops I conducted have served to further illustrate the operation in theatre audiences of embodied and kinaesthetic empathy. Groups of school children, aged between 12 and 15, took part in a series of four workshops, two to three weeks after a physical theatre performance of Mojo-Mickybo by Owen McCafferty, in which two actors had portrayed seventeen characters between them using a physical performance style which established clearly delineated physical types for each role. After a warm-up in which the 'Samson, Delilah and the Lion' game was adapted to include three of the characters from the play, workshop participants were invited to recall some of the others. In the majority of cases, the participants were observed to reenact the character's body posture first, before recalling the character names. In some cases, the name had been forgotten, but the physical motif was retained in the memory.
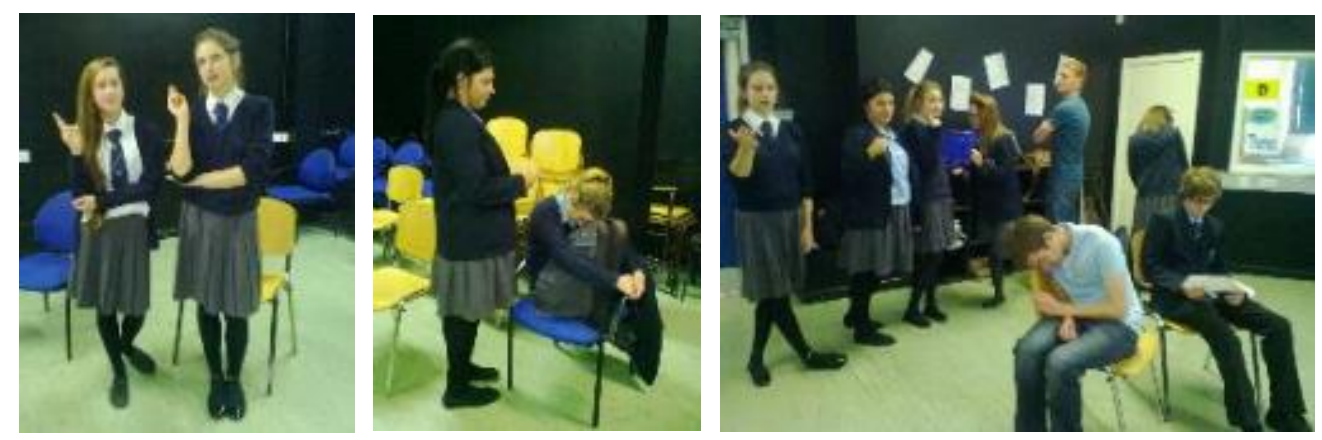

External observers can therefore be seen to go through a simultaneous process to that of the image-makers, arriving at a blend of the semiotic and phenomenological as interpretation and empathy combine as a range of meanings coalesces around the emerging image. It is important to note that this is a dynamic process, since the observers are able to experience the image taking shape, and each observer may experience a series of different responses as the image develops. It is a core principle of the Theatre of the Oppressed that while the widest possible range of reactions to a stage image should be solicited from all those that experience it, the process is not aimed at arriving at a consensus. This concept has been succinctly summed up by Teya Sepinuck, the Artistic Director and founder of the Theatre of Witness which provides the opportunity for its performers to put their own (often deeply traumatic) stories on stage, as "holding the paradox'.

Baz Kershaw has distinguished between an oxymoron and a paradox: 
An oxymoron - such as 'extremes meet' - is a coupling of (usually) two words/terms/subjects with no mediating factor, simply a clash of meanings which never resolves... Whereas paradoxes (especially strong ones) tend to yoke together contradicting statements in ways that relate ambivalently and so are capable of producing a range of interpretations which do not exclude 'over-riding truths'. (email to author 20/3/2013)

This idea of a 'range of truths' is central to Boal's practice, and can be seen in the importance attached by Boal to the open-endedness of images created through the Image Theatre process.

\section{Conclusion}

This article has sought to understand Boal's Image Theatre as a shared embodied process in which the distinctions between meaning and feeling, and between the observer and the observed become blurred. In Image Theatre, image makers are encouraged through the use of the exercises from Boal's 'Arsenal of the Oppressed' to work intuitively, enabling them to function as holistic organisms capable of corporeal thought, manifesting intuitive 'unknown knowns' as embodied knowledge through stage images. Those viewing the images can engage not only intellectually and semiotically through the reading of signs but also intuitively and phenomenologically through a process of kinaesthetic empathy.

In his visionary book, Orality and Literacy (1982), Walter Ong anticipated that the spread of the internet would bring forth a period of "secondary orality" in which writing would become subordinate to the spoken word. The increasing availability online of 'streamed' video and the ability to search the worldwide web for images suggests however that alongside the ideas of literacy and orality we now also need to include 'imageracy', the ability to interpret and understand images, as a key competency in the modern world. Training in the techniques of Image Theatre, both in the making and receiving of stage images must surely have an important role to play in helping address this emerging educational challenge. This in turn will require a theoretical basis for the processes that underpin both the creation of stage images and their interpretation. It is hoped that this article has identified some key concepts in psychology which will help inform a developing understanding of Image Theatre.

\section{References}

Bergson, Henri (1889). Time and Free Will: An Essay on the Immediate Data of Consciousness, trans. F.L. Pogson (London: George Allen and Co., 1913)

(1979). Theatre of the Oppressed (London: Pluto Press)

(2002). Games for Actors and Non-Actors, 2nd Edition (London: Routledge)

. (1995). The Rainbow of Desire (London: Routledge)

Cole, Gallagher and McNeill (2002). 'Gesture following deafferentation: A phenomenologically informed experimental study' in Phenomenology and the Cognitive Sciences, 1:49-67

De Saussure, F. (1974) Course in General Linguistics (New York, Fontana/Collins) 
Gallagher, S (2005). How the Body Shapes the Mind (Oxford: Clarendon Press)

McConachie, B and H.E. Hart (eds.) (2006). Performance and Cognition: Theatre Studies After the Cognitive Turn (Routledge)

Merleau-Ponty, M. (1962). Phenomenology of Perception, tr. C. Smith. (London: Routledge and Kegan Paul)

Ong, Walter (1982). Orality and Literacy: The Technologizing of the Word (London: Routledge)

Perry, J. Adam (2012) A silent revolution: 'Image Theatre' as a system of decolonisation, Research in Drama Education: The Journal of Applied Theatre and Performance, 17:1, 103-119, DOI: 10.1080/13569783.2012.648991

Reynolds, D. \& M. Reason (eds.) (2012). Kinaesthetic Empathy in Creative and Cultural Practices (Intellect)

Steiner, George (1998). After Babel: Aspects of language and translation (3rd Edition) (Oxford: OUP)

Strecker, I (1997). 'The Turbulence of Images: on imagery, media and ethnographic discourse' Visual Anthroplogy 9 